\title{
USE OF RED MUD AND IRON TAILINGS IN SELF COMPACTING CONCRETE
}

\author{
Kiran K. Shetty ${ }^{1}$, Gopinatha Nayak ${ }^{2}$, Vipul Vijayan ${ }^{3}$ \\ ${ }^{1}$ Associate Professor (Senior Scale), Department of Civil Engineering, Manipal Institute of Technology, Manipal \\ ${ }^{2}$ Associate Professor, Department of Civil Engineering, Manipal Institute of Technology, Manipal \\ ${ }^{3} M$-tech Student, Department of Civil Engineering, Manipal Institute of Technology, Manipal
}

\begin{abstract}
Cost reduction in the building is the primary objective in developing countries like India. To achieve this objective, intensive efforts are being made in effective utilization of waste and by products particularly from mining and mineral industries. Keeping this in mind, a study on self-compacting concrete (SCC) using red mud as partial replacement for cementitious material along with iron tailings as partial replacement for sand is made. Cementitious material in the mixture was replaced with red mud at $1 \%$, $2 \%, 3 \%$ and $4 \%$. For each red mud replacement level, $10 \%$ of fine aggregate (regular sand) was replaced with iron tailings
\end{abstract}

Keywords: Red mud, Self-Compacting concrete (SCC), Iron tailings.

\section{INTRODUCTION}

Building products that have a portion of their constituent materials from recycled products reduce the need for virgin materials in new construction. Recycled materials such as Fly Ash, Red Mud, Silica Fume are used as a partial replacement for Portland cement in concrete and Quarry Dust, used foundry sand, Mine Tailings are some of the waste materials used as aggregate in concrete. Use of such materials would minimize the use of scarce materials and also generate appreciable economy. Also use of waste byproducts has greater potential because $70-80 \%$ of concrete is composed of aggregates.

Kushwaha et al. have reported that the use of red mud as an admixture up to $2 \%$ will improve the compressive strength and if over $2 \%$ of red mud is added then the strength starts decreasing [1]. Aruna Mangalpady mentioned in his paper that the composition of tailings is directly dependent on the composition of the ore and the process of mineral extraction used on the ore. He studied the suitability and reliability of Iron ore tailings in manufacture of Paving Blocks. He prepared five reference mixes using cement, jelly dust and baby jelly with different mix ratios and by using sand and Iron ore tailings as fine aggregates. The results of his study showed that compressive strength of tailing based mix was higher than the respective reference mix [2]. Ullas et al., did experimental study on masonry units made of Iron ore tailings in compressed earth block (CEB). In that they used optimum mix proportions of soil, sand and cement and the sand fraction is replaced by Iron ore tailings (IOT) at $25 \%$, $50 \%$ and $100 \%$. They checked block characteristics like wet compressive strength, water absorption, initial rate of absorption, linear elongation and they found that considerable amount of sand can be replaced by IOT without compromising desirable characteristics of CEB [3]. Sujing et al., studied the possibility of using Iron ore tailings to replace natural aggregate to prepare ultra - high performance concrete (UHPC). It was found that the 100\% replacement of natural aggregate by Iron ore tailings significantly replaced the workability and compressive strength of material. However when the replacement level was not more than $40 \%$, for 90 days standard cured specimens, the mechanical behavior of the tailings was comparable to that of control mix and for specimens that were steam cured for 2 days, the compressive strengths of the tailing mixes decreased by $11 \%$ while the flexural strength increased by up to $8 \%$ compared to the control mix [4]. Xiaoyan Huang et al., used an attempt to use Iron ore tailings to develop greener engineered cementious composites (ECCs). He found that, with a cement content $117.2-350.2 \mathrm{~kg} / \mathrm{m} 3$, exhibit a tensile ductility of $2.3-3.3 \%$, tensile strength of $5.1-6 \mathrm{MPa}$ and compressive strength of $46-57 \mathrm{MPa}$ at 28 days [5].

In this paper we prepared self-compacting concrete by partially replacing cementitious material by red mud (RM) and in the same mix we have also partially replaced sand by iron ore tailings. Cementitious material in the mixture was replaced with red mud at $1 \%, 2 \%, 3 \%$ and $4 \%$. For each red mud replacement level, $10 \%$ of fine aggregate (regular sand) was replaced with Iron Ore Tailings.

\section{EXPERIMENTAL PROGAMME}

\subsection{Materials Used}

\subsubsection{Cement}

Ordinary Portland cement (43 grade) was used in this study. The cement was tested according to IS: 8112-1989 [5]. The specific gravity was found to be 3.1 .

\subsubsection{Fly Ash}

The fly ash used in this study was obtained from Raichur Thermal Power Plant Station (RTPS). As the fly ash 
produced by Raichur Thermal Power Plant Station (RTPS) contain less carbon content and are extremely finer than any other source. This enable to study the SCC mixes containing fly ash incorporation. The specific gravity was found to be 2.23 .

\subsubsection{Red Mud}

Red mud is a waste material generated by the Bayer process widely used to produce alumina from bauxite. In the Bayer process, the insoluble product generated after bauxite digestion with sodium hydroxide at elevated temperature and pressure to produce alumina is known as red mud or bauxite residue. The waste product derives its color and name from its iron oxide content. The red mud used in this study was obtained from Hindalco Industries Limited, Belgaum, and Karnataka. The red mud used in this study was sieved through $600 \mu$ sieve. The specific gravity was found to be 2.807 .

\subsubsection{Fine Aggregate}

Natural river sand with maximum size of $4.75 \mathrm{~mm}$ was used in this study. The specific gravity was found to be 2.64 .

\subsubsection{Iron Ore Tailings}

Iron ore tailings are the materials left over after the beneficiation process of separating the valuable fraction from the worthless fraction of an iron ore. The various processes of beneficiation are crushing, screening, grinding, washing, jigging, cycloning, using magnetic separator etc. Even though left over iron ore tailing contains $20-30 \%$ of iron, further extraction from it will be costly. The composition of tailings is directly dependent on the composition of the ore and the process of mineral extraction used on the ore. Its specific gravity is found to be 3.24

\subsubsection{Coarse Aggregate}

SCC can be made from most normal concreting aggregates. Coarse aggregates differ in nature and shape depending on their extraction and production. SCC has been produced successfully with coarse aggregates up to $40 \mathrm{~mm}$, however these trials are made keeping maximum aggregate size of 12 $\mathrm{mm}$. The coarse aggregates, obtained from a local source, had a specific gravity of 2.65. The size fraction of the coarse aggregate used is extremely important for determining the optimum amount of paste content to obtain all the necessary characteristics of a flowing concrete. The fine and coarse aggregates were tested according to IS: 383-1970 [6].

\subsubsection{Admixture}

Admixtures are essential in determining flow characteristics and workability retention. Ideally, they should also modify the viscosity to increase cohesion. Newly developed types of super plasticizer, known as Poly-Carboxylate Ethers (PCE), are particularly relevant to SCC. They reconcile the apparently conflicting requirements of flow and cohesion, avoiding potential problems and unwanted retardation and excessive air entrainment, particularly at higher workability if the mix design is correct. The admixture used in the current program was Algihyperplast $\mathrm{N}$ supplied by ALGI. ALGIHYPERPLAST-N is powerful Naphthalene based super plasticiser recommended of site mixed concrete or for concrete which requires high early strength or where concrete is placed within half an hour of mixing.

\subsection{Concrete Mix Proportions}

In this study five concrete mix proportions were made(Table- 1). The first mix was a controlled mix (without red mud and IOT) and the remaining four mixtures contained red mud and IOT. The controlled SCC mix was designed for M25 grade. EFNARC [8] guidelines were followed to design the SCC mix. Cementitious material in the mixture was replaced with red mud at $1 \%, 2 \%, 3 \%$ and $4 \%$. For each red mud replacement level, $10 \%$ of fine aggregate (regular sand) was replaced with Iron Ore Tailings (IOT).

Table - 1: Concrete mixture proportion

\begin{tabular}{|l|l|l|l|l|l|}
\hline Mixture No. & NSCC & RM-1 & RM-2 & RM-3 & RM-4 \\
\hline Cement $\left(\mathrm{kg} / \mathrm{m}^{3}\right)$ & 367.5 & 365.66 & 363.82 & 361.98 & 360.15 \\
\hline Fly ash $\left(\mathrm{kg} / \mathrm{m}^{3}\right)$ & 332.5 & 330.83 & 329.17 & 327.51 & 325.85 \\
\hline Red mud $(\%)$ & 0 & 1 & 2 & 3 & 4 \\
\hline Red mud $\left(\mathrm{kg} / \mathrm{m}^{3}\right)$ & 0 & 7 & 14 & 21 & 28 \\
\hline Iron ore tailings $(\%)$ & 0 & 10 & 10 & 10 & 10 \\
\hline Iron ore tailings $\left(\mathrm{kg} / \mathrm{m}^{3}\right)$ & 0 & 63.235 & 63.235 & 63.235 & 63.235 \\
\hline Water $\left(\mathrm{kg} / \mathrm{m}^{3}\right)$ & & & & & \\
\hline W/C & 212.8 & 212.8 & 212.8 & 212.8 & 212.8 \\
\hline Sand $\left(\mathrm{kg} / \mathrm{m}^{3}\right)$ & 0.304 & 0.304 & 0.304 & 0.304 & 0.304 \\
\hline Coarse aggregate $\left(\mathrm{kg} / \mathrm{m}^{3}\right)$ & 632.35 & 569.115 & 569.115 & 569.115 & 569.115 \\
\hline Super plasticizer $\left(1 / \mathrm{m}^{3}\right)$ & 689.05 & 702.89 & 703.14 & 703.37 & 703.61 \\
\hline
\end{tabular}




\subsection{Preparation and Casting of Specimens}

$150 \times 150 \times 150 \mathrm{~mm}$ cubes were casted for compressive strength. For split tensile strength $150 \times 300 \mathrm{~mm}$ cylinders were casted. For the flexural strength beams of $100 \times 100 \times$ $500 \mathrm{~mm}$ were casted. After casting, all the test specimens were kept at room temperature for 24 hours and then demoulded. These were then placed in the water curing tank.

\subsection{Properties of Fresh Concrete}

The properties of fresh concrete such as slump, passing ability, filling ability and segregation resistance were determined according to EFNARC specifications. The tests carried out to determine these properties were slump flow test, $\mathrm{T}-500$ test, $\mathrm{L}-$ box test, $\mathrm{V}-$ funnel test and $\mathrm{U}-$ box test.

\subsection{Properties of Hardened Concrete}

The compressive strength tests on the cubes were performed at ages 7 and 28 days. The split tensile tests on cylinders and the flexural strength tests on beams were performed at 28 days. All tests were performed in accordance with the provisions of IS: 516-1959 [9].

\section{RESULTS AND DICUSSIONS}

Table-2: Compressive strength, Tensile strength and Flexural strength with respect to mix proportions

\begin{tabular}{|l|l|l|l|l|l|}
\hline MIX NO & \multirow{2}{*}{$\begin{array}{l}\text { MIX } \\
\text { PROPORTIONS }\end{array}$} & COMP. STRENTH OF CUBES (MPa) & TENSILE & $\begin{array}{l}\text { FLEXURAL } \\
\text { STRENGTH } \\
\text { CYLINDERS (MPa) }\end{array}$ & $\begin{array}{l}\text { STRENGTH OF } \\
\text { BEAMS (MPa) }\end{array}$ \\
\cline { 3 - 6 } & & 7 Days & 28 Days & 3.45 & 6.23 \\
\hline 1 & NSCC & 24.8 & 32.8 & 3.21 & 6.35 \\
\hline 3 & RM-1 & 28.56 & 32.91 & 3.50 & 6.63 \\
\hline 4 & RM-2 & 31.78 & 37.10 & 3.108 & 6.2 \\
\hline 5 & RM-3 & 29.648 & 33.31 & 2.886 & 6.121 \\
\hline
\end{tabular}

\subsection{Compressive Strength}

The concrete mixtures were made with the controlled mix as well as with red mud and IOT to check the compressive strength for 28 days of curing. The results are shown in fig.1. At 28-day, the control mixture NSCC (0\% RM, 0\% IOT) achieved a compressive strength of $32.8 \mathrm{MPa}$. The mixtures RM-1(1\% RM, 10\% IOT), RM-2 (2\% RM, $10 \%$ IOT), RM-3(3\% RM, 10\% IOT) and RM-4(4\% RM, $10 \%$ IOT) achieved compressive strengths of $32.91 \mathrm{MPa}, 37.103$ $\mathrm{MPa}, 33.31 \mathrm{MPa}$ and $30.32 \mathrm{MPa}$ respectively. An increase of $0.33 \%, 13.11 \%$, and $1.55 \%$ was observed for RM-1, RM2 and RM-3 respectively with respect to NSCC. A decrease of $7.56 \%$ was observed for RM-4.

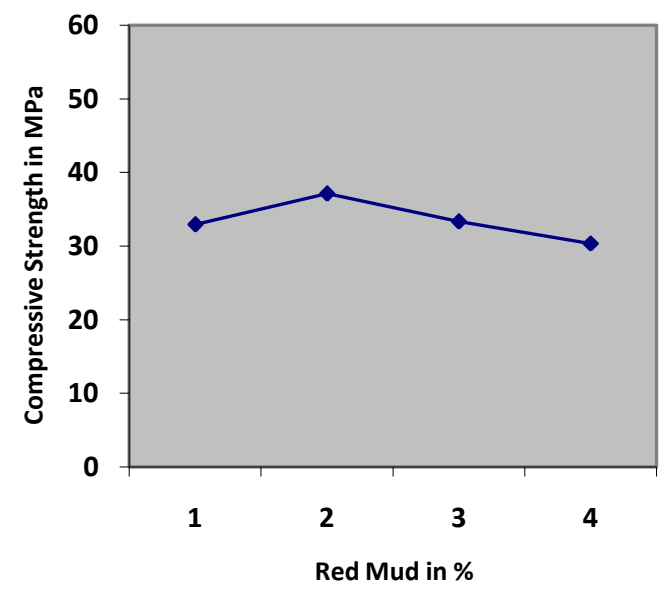

\subsection{Splitting-Tensile Strength}

The split tensile strength is shown in fig.2. At 28-day, the control mixture NSCC achieved a split-tensile strength of 3.45 MPa. The mixtures RM-1, RM-2, RM-3 and RM-4 achieved splitting-tensile strengths of $3.21 \mathrm{MPa}, 3.50 \mathrm{MPa}$, $3.108 \mathrm{MPa}$ and $2.886 \mathrm{MPa}$ respectively. The maximum tensile strength is obtained at 2\% RM $10 \%$ IOT. After this the tensile strength kept on decreasing.

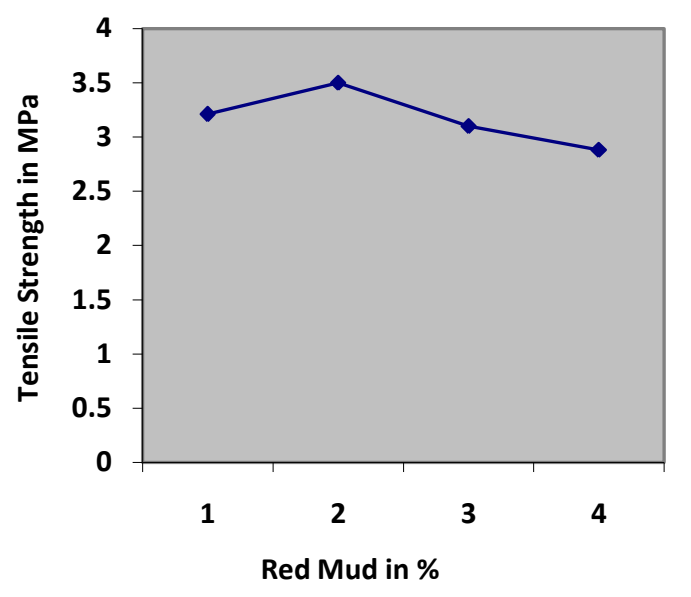

Fig. 2: Split tensile strength in relation to red mud content

Fig. 1: Compressive strength in relation to red mud content. 


\subsection{Flexural Strength}

The flexural strength is shown in fig.3. At 28-day, the control mixture NSCC achieved a flexural strength of 6.23 MPa. The mixtures RM-1, RM-2, RM-3 and RM-4 achieved flexural strengths of $6.35 \mathrm{MPa}, 6.63 \mathrm{MPa}, 6.2 \mathrm{MPa}$ and $6.121 \mathrm{MPa}$ respectively. The maximum flexural strength was achieved at $2 \%$ red mud with $10 \%$ IOT. After this the flexural strengths reduced marginally. The flexural strength achieved for all the mix is more than the control mix and all these values are more than IS specified values. . An increase of $1.926 \%$ and $6.42 \%$ was observed for RM-1 and RMrespectively with respect to NSCC. A decrease of $0.48 \%$ and $1.75 \%$ was observed for RM-3 and RM-4 compared to NSCC.

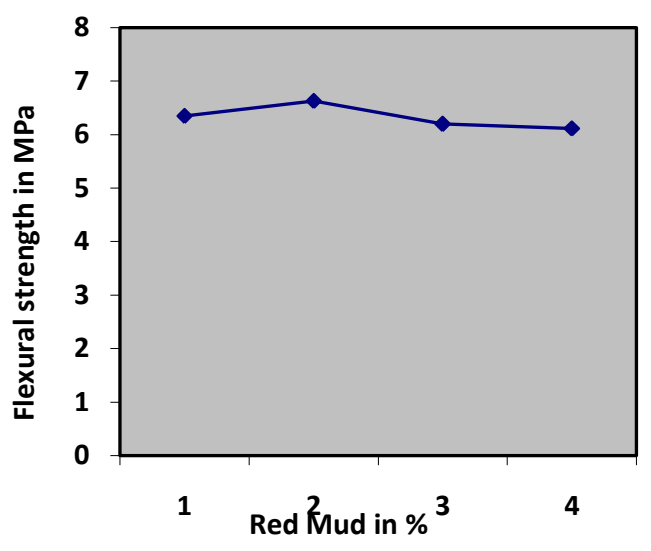

Fig. 3: Flexural strength in relation to red mud content

\section{CONCLUSIONS}

Following conclusions were drawn from the experimental results of this study:

1. The maximum compressive strength was achieved at $2 \%$ red mud with $10 \%$ IOT. The compressive strength increased by $13.11 \%$ for this mix.

2. The tensile strength achieved for $2 \%$ Red Mud with

$10 \%$ IOT is more compared to other mixes and is Increased by $1.5 \%$.

3. The maximum flexural strength was achieved at $2 \%$ red mud with $10 \%$ IOT. The flexural strength increased by $6.42 \%$ at for this mix.

\section{REFERENCES}

[1] Mohan Kushwaha, Dr. Salim Akthar and Aurvesh Rajput, (2013) "Development of the self-compacting concrete by industrial waste (Red Mud)", International Journal of Engineering Research Applications (IJERA), Vol.3, Issue 4, pp. 539-542.

[2] Mangalpady Aruna, (2012) "Utilization of Iron Ore Tailings in manufacturing of paving blocks for ecofriendly mining", IC-GWBT2012, Ahmad Dahlan University, March 23-24, 2012.

[3] Ullas S N and B V Venkatarama Reddy, (2010)“ Iron ore tailings as substitute for sand in masonry mortar", Proceedings of the International Seminar on Waste to Wealth, New Delhi, India, 2009, pp. 151-155.
[4] Sujing Zhao, Junjiang Fan and Wei Sun, (2010) "Utilization of iron ore tailings as fine aggregate in ultra-high Performance concrete", Construction and Building Materials, pp. 540-548.

[5] Xiaoyan Huang, Ravi Ranade, Wen Ni and Victor C. $\mathrm{Li}$, (2013) "Development of green engineered cementitious composites using iron ore tailings as aggregates", Construction and Building Materials, pp. $757-764$.

[6] IS: 8112-1989, Specification for 43-Grade Portland Cement, New Delhi, India: Bureau of Indian Standards.

[7] IS: 383-1970, Specifications for coarse and fine aggregates from natural sources for concrete, New Delhi, India: Bureau of Indian Standards.

[8] The European guidelines for self-compacting concrete: specification, production and use. EFNARC, May 2005.

[9] IS: 516-1959, Indian Standard code practicemethods of test for strength of concrete, New Delhi, India: Bureau of Indian Standards.

\section{BIOGRAPHIES}

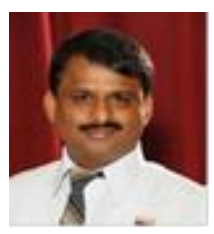

Dr. Kiran K. Shetty obtained his B.E degree in Civil Engineering at N.M.A.M.I.T., Nitte under Mangalore University in the year 1998. He received his postgraduate degree at M.I.T., Manipal in Structural Engineering with Second Rank under Visveswaraiah Tech. University, Belgaum in the year 2000. Further, he obtained his Ph.D. from the Manipal Academy of Higher Education (MAHE), Manipal in the year 2006. He is presently working as Associate Professor (Senior Scale) in the department of Civil Engineering, Manipal Institute of Technology, Manipal. He has over 14 years of teaching experience. He has to his credit about 50 technical papers in various national and International journals and conferences.

Dr. Gopinatha Nayak obtained his Ph.D. in Structural Engineering from NITK, Suratkal. He is presently working as Associate Professor of Department of Civil Engineering, MIT Manipal University, $\mathrm{He}$ has presented several papers in National Seminar/Conferences and also published papers in National/international Journals. His area of interest includes Concrete technology, structural design and analysis

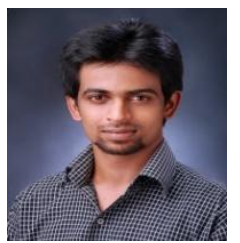

Vipul Vijayan, is presently pursuing his M.Tech in Structural Engineering in MIT, Manipal. He received his B.Tech Degree in Civil Engineering from Nitte University, Nitte, Karnataka. $\mathrm{He}$ has presented several papers in National conferences. His areas of interest incudes structural design and analysis 